\title{
ESTUDOS SEDIMENTOLÓGICOS DAS FORMAÇÕES BOTUCATU E PIRAMBÓIA NA REGIÃO DE SANTA RITA DO PASSA QUATRO, SP
}

\author{
ANNA ARTEMISIA BARRACCO DE AZEVEDO * \\ MÁRCIA MARIA NOGUEIRA PRESSINOTTI * \\ MARCOS MASSOLI *
}

\begin{abstract}
RESUMO
Os estudos sedimentológicos realizados em 28 amostras de arenito tiveram por objetivo a caracterização, mediante parâmetros estatísticos de FOLK \& WARD, das Formações Botucatu e Pirambóia, na folha de Santa Rita do Passa Quatro. Os dados obtidos revelaram, para estas duas Formações, diferenças marcantes nos seus valores de grau de seleção e curtose, ao passo que a assimetria mostrou valores bastante próximos.

Através da distribuição granulométrica das amostras, pode-se fazer uma cllassificação desses sedimentos, segundo SHEPPARD, bem como construir os gráficos denominados Sedimentogramas, que contribuíram nas interpretações dos ambientes deposicionais das referidas Formações.
\end{abstract}

\section{ABSTRACT}

This text presents sedimentologic studies through statistical analysis, in 28 sandstones samples from the Botucatu and Pirambóia Formations. The area is located nearby Santa Rita do Passa Quatro, in the Northeast part of the São Paulo State.

The data obtained showed different statistical values for the geologic formations, being the sorting coefficient and kurtosis different, but the skewness similar.

A sediment classification (SHEPPARD) was carried out with the particle size distribution. The size distribution graphic (Sedimentograma) allowed to study the sediments behaviours during transport and deposition.

\section{INTRODUÇÃO}

Por ocasião do mapeamento geológico da folha topográfica de Santa Rita do Passa Quatro, escala 1:50.000, ficou constatada a presença de arenitos cuja posição estratigráfica confunde-se ora com os arenitos da Formação Botucatu, ora com os arenitos da Formação Pirambóia, (MASSOLI 1980 ). Isto motivou o desenvolvimento do presente estudo, que teve dois principais objetivos: a) caracterização sedimentológi-

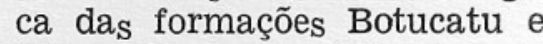
Pirambóia, para efeito de mapeamento destas unidades, tendo em vista a uniformidade textural e estrutural destes sedimentos na região;

b) estudo das análises granulométricas como um método adequado para a caracterização e diferenciação de ambientes deposicionais.

\footnotetext{
* Geólogos - Seção de Estudos Geológicos - Instituto Geológico.
} 


\section{LOCALIZAÇÃO}

A área onde foram estudados os sedimentos mencionados, situa-se a NE do Estado de São Paulo. Está dentro da região abrangida pela folha topográfica de Santa Rita do Passa Quatro, escala 1:50.000, IBGE, compreendida entre os paralelos $21^{\circ} 30^{\prime}$ e $21^{\circ} 45^{\prime}$ e entre os meridianos $47^{\circ} 15^{\prime}$ e $47^{\circ} 30^{\prime}$.

\section{ASPECTOS GEOLÓGICOS E GEOMORFOLÓGICOS}

A área pesquisada, localizada na borda Leste da Bacia do Paraná, apresenta de baixo para cima as seguin-

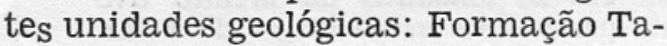
tuí, composta por siltitos arenosos; Formação Estrada Nova constituída de siltitos e argilitos arroxeados e avermelhados; Formação Botucatu e Pirambóia, apresentando arenitos rosados e avermelhado ${ }_{S}$ e arenitos conglomeráticos; Formação Serra Geral e in-

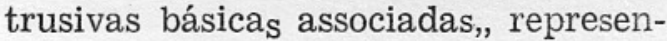
tadas por basaltos e diabásios; sedimentos terciários, constituidos por areias inconsolidadas com linhas de seixos na base; e depósitos aluviais recentes (Figura 1).

Geomorfológicamente predomina a província das "Cuestas Basálticas". A "Depressão Periférica" aparece em pequena escala a SW, E-SE e NE da área.

\section{FORMAÇÃO BOTUCATU E/OU PIRAMBÓIA}

Sob os derrames basálticos e acima da Formação Estrada Nova ocorrem arenitos homogêneos de cores avermelhadas, às vezes apresentando coloração acastanhada e muito raramente amarelada. Pelas suas características macroscópicas, descritas adiante, não foi possível determinar a formação geológica à qual pertencem, isto é, se Fm. Botucatu de origem eóli- ca, ou se Fm. Pirambóia de origem fluvial, segundo WASHBURNE (1930).

MEZZALIRA (1965) no mapa geológico da folha topográfica de Casa Branca, na escala $1: 100.000$. situou esses arenitos na Fm. Botucatu. No mapa geológico da PETROBRÁS (1971) na escala $1: 100.000$, esses sedimentos foram separados em duas unidades geológicas ( $\mathrm{Fm}$ Botucatu e Fm Pirambóia), o mesmo ocorrendo no mapa executado pela CPRM (1977, Projeto Sapuicaí), na escala 1:250.000.

No mapa geológico da folha de Santa Rita do Passa Quatro MASSOLI (1980), esse pacote de arenitos permaneceu indiviso por se apresentar macroscopicamente homogêneo, o que motivou o estudo sedimentológico detalhado de tais sedimentos para verificação da possível existência de duas unidades sedimentares distintas.

Segundo SOARES (1973), na base do arenito Botucatu ocorre, geralmente, uma camada de arenito conglomerático, que foi encontrada na área pesquisada, porém em zona de falha, não fornecendo, portanto, a posição estratigráfica real do referido sedimento.

Esses sedimentos indivisos são constituidos por arenitos de granulação variando entre média a fina, às vezes grosseira, com matriz síltico-argilosa em porcentagens variadas.

Sua composição é essencialmente quartzosa, apresentando grãos subarredondados a sub-angulosos. Foi observada, também, pequena quantidade de minerais ferromagnesianos.

Esses arenitos apresentam acamamento plano paralelo e estratificação cruzada de pequeno a médio porte, tangencial na base, podendo tratar-se de uma sedimentação em ambiente tanto fluvial como eólico.

O contato desses arenitos com os siltitos da Formação Estrada Nova é 
marcado por uma discordância erosiva onde se encontra uma camada constituída por fragmentos de silex e siltitos em matriz areno-argilosa.

\section{SEDIMENTOLOGIA}

\section{Amostragem}

Foram coletadas 28 amostras de arenito, do tipo pontual, devido à homogeneidade apresentada nos afloramentos. Cada amostra, com cerca de $1 \mathrm{~kg}$ de peso, foi guardada em sacos plásticos devidamente rotulados, para posterior ensaio.

\section{Análise granulométrica}

As amostras foram processadas em laboratório através da combinação de métodos de peneiramento, para partículas maiores que $0,062 \mathrm{~mm}$ (areias), e pipetagem, para frações menores que $0,062 \mathrm{~mm}$ (siltes e argilas).

Obtidas as porcentagens em peso das $_{\text {diferente }}$ frações granulométricas das amostras analisadas, construiramse em papel de probabilidade aritmética, as curvas de frequência acumulada correspondentes, estando no eixo das abcissas o diâmetro em $\mathrm{mm}$ e no das ordenadas uma escala de frequência, variando de 0 a $100 \%$. Estas curvas de frequência é que forneceram os dados com os quais foram calculados os parâmetros estatísticos de FOLK \& WARD, SUGUIO (1973).

\section{ANÁLISE ESTATÍSTICA}

A tabela a seguir mostra os parâmetros estatísticos obtidos através das análises granulométricas, levando-se em conta a distribuição total de cada amostra.

\section{a) CASSIFICAÇÃO DE SHEPPARD}

Segundo SHEPPARD, SUGUIO (1973), um sedimento que contenha acima de $75 \%$ da fração areia é classificado como arenito; contendo entre $50 \%$ e $75 \%$ é classificado como are- nito siltoso ou argiloso, dependendo da quantidade de silte ou argila, respectivamente. Assim sendo, dentre as 28 amostras estudadas, 25 são arenitos, 2 arenitos siltosos e 3 arenitos argilosos.

SOARES (1975) constatou que a Fm. Pirambóia, na região NE do Estado, apresenta um teor em lama (silte+ argila) de $20 \%$, duas vezes maior que o da Fm. Botucatu. Baseado nisto, as amostras areno-siltosas e areno-argilosas foram classificadas como pertencentes à Fm. Pirambóia.

Observando-se os parâmetros estatísticos das 23 amostras restantes, arenitos segundo SHEPPARD, verificou-se que ocorre uma grande variação em seus valores, o que sugere ambientes deposicionais diferentes. Desse modo, parte destes arenitos podem pertencer à $\mathrm{Fm}$. Botucatu e parte à Fm. Pirambóia.

Tomando-se como base os parâmetros das 5 amostras já classificadas como Pirambóia (arenitos siltosos e argilosos), fez-se uma comparação com os parâmetros dos outros sedimentos classificados como arenito, no intuito de distinguir as duas unidades.

\section{b) DIÂMETRO MÉDIO}

Comparando-se os diâmetros médios das amostras classificadas como pertencentes à $\mathrm{Fm}$. Pirambóia (amostras $04,16,24,82,94$ ), cujos valores variam de areia muito fina a silte grosso com os diâmetros médios das demais amostras, cujos valores variam de areia média a areia muito fina, verificou-se que este parâmetro não constitui um critério para determinar a unidade sedimentar da amostra, pois os valores encontrados são muito próximos.

\section{c) GRAU DE SELEÇÃO}

Como os sedimentos da Fm. Botucatu são de origem eólica, enquanto que os da Fm. Pirambóia são fluviais, 
Rev. IG, São Paulo, 2(1):31-38, jan./jun. 1981

\begin{tabular}{|c|c|c|c|c|c|c|}
\hline Amostra & $\begin{array}{l}\% \text { de areia } \\
\text { silte } \\
\text { argila }\end{array}$ & $\begin{array}{l}\text { Class. de } \\
\text { Sheppard }\end{array}$ & $\begin{array}{l}\text { Diam. } \\
\text { Médio } \\
(\mathrm{mm})\end{array}$ & $\begin{array}{l}\text { Grau de } \\
\text { seleção }\end{array}$ & $\begin{array}{l}\text { Grau de } \\
\text { Assimetria }\end{array}$ & Curtose \\
\hline 02 & $\begin{array}{r}79,9 \\
7,2 \\
12,8 \\
\end{array}$ & arenito & $\begin{array}{r}0,059 \\
\text { sil. gr. }\end{array}$ & $\begin{array}{r}1,900 \\
\text { pob. } \mathrm{s} .\end{array}$ & $\begin{array}{c}0,852 \\
\mathrm{~m} .+\end{array}$ & $\begin{array}{l}2,685 \\
\text { m. lep. }\end{array}$ \\
\hline 04 & $\begin{array}{l}62,7 \\
16,5 \\
20,7 \\
\end{array}$ & $\begin{array}{l}\text { arenito } \\
\text { argiloso }\end{array}$ & $\begin{array}{r}0,043 \\
\text { sil. gr. }\end{array}$ & $\begin{array}{r}2,780 \\
\text { m. pob. s. }\end{array}$ & $\begin{array}{c}0,435 \\
\mathrm{~m} .+\end{array}$ & $\begin{array}{l}0,653 \\
\text { m. pl. }\end{array}$ \\
\hline 15 & $\begin{array}{r}81,9 \\
9,0 \\
9,0\end{array}$ & arenito & $\begin{array}{r}0,117 \\
\text { ar.m.f. }\end{array}$ & $\begin{array}{r}1,900 \\
\text { pob. } \mathrm{s} .\end{array}$ & $\begin{array}{r}0,607 \\
\mathrm{~m} .+\end{array}$ & $\begin{array}{r}0,830 \\
\text { pl. }\end{array}$ \\
\hline 16 & $\begin{array}{l}71,0 \\
14,4 \\
14,5\end{array}$ & $\begin{array}{l}\text { arenito } \\
\text { argiloso }\end{array}$ & $\begin{array}{r}0,068 \\
\text { ar.m.f. }\end{array}$ & $\begin{array}{r}2,466 \\
\text { m. pob. s. }\end{array}$ & $\begin{array}{c}0,604 \\
\mathrm{~m} .+\end{array}$ & $\begin{array}{r}1,365 \\
\text { lep. }\end{array}$ \\
\hline 21 & $\begin{array}{r}78,4 \\
8,8 \\
12,7 \\
\end{array}$ & arenito & $\begin{array}{r}0,067 \\
\text { ar.m.f. }\end{array}$ & $\begin{array}{r}1,867 \\
\text { pob. s. }\end{array}$ & $\begin{array}{c}0,828 \\
\mathrm{~m} .+\end{array}$ & $\begin{array}{l}2,889 \\
\text { m. lep. }\end{array}$ \\
\hline 22-A & $\begin{array}{r}86,7 \\
8,0 \\
5,3\end{array}$ & arenito & $\begin{array}{l}0,159 \\
\text { ar. f. }\end{array}$ & $\begin{array}{r}1,199 \\
\text { pob. } \mathrm{s} .\end{array}$ & $\begin{array}{c}0,580 \\
\mathrm{~m} .+\end{array}$ & $\begin{array}{c}3,548 \\
\text { ext. lep. }\end{array}$ \\
\hline 22-B & $\begin{array}{r}80,7 \\
7,9 \\
11,4\end{array}$ & arenito & $\begin{array}{r}0,083 \\
\text { ar.m.f. }\end{array}$ & $\begin{array}{r}1,478 \\
\text { pob. s. }\end{array}$ & $\begin{array}{c}0,612 \\
\mathrm{~m} .+\end{array}$ & $\begin{array}{c}3,091 \\
\text { ext. lep. }\end{array}$ \\
\hline 23 & $\begin{array}{r}88,0 \\
1,9 \\
10,1 \\
\end{array}$ & arenito & $\begin{array}{l}0,156 \\
\text { ar. f. }\end{array}$ & $\begin{array}{r}1,258 \\
\text { pob. s. }\end{array}$ & $\begin{array}{c}0,678 \\
\text { m. + }\end{array}$ & $\begin{array}{c}4,545 \\
\text { ext. lep. }\end{array}$ \\
\hline 24 & $\begin{array}{l}71,7 \\
12,1 \\
16,2\end{array}$ & $\begin{array}{l}\text { arenito } \\
\text { argiloso }\end{array}$ & $\begin{array}{r}0,049 \\
\text { sil. gr. }\end{array}$ & $\begin{array}{r}2,583 \\
\text { m. pob. s. }\end{array}$ & $\begin{array}{l}0,650 \\
\mathrm{~m} .+\end{array}$ & $\begin{array}{r}1,198 \\
\text { lep. }\end{array}$ \\
\hline 25 & $\begin{array}{r}85,1 \\
9,5 \\
5,4\end{array}$ & arenito & $\begin{array}{l}0,144 \\
\text { ar. f. }\end{array}$ & $\begin{array}{r}1,474 \\
\text { pob. s. }\end{array}$ & $\begin{array}{c}0,558 \\
\mathrm{~m} .+\end{array}$ & $\begin{array}{l}2,293 \\
\text { m. lep. }\end{array}$ \\
\hline 26 & $\begin{array}{r}84,6 \\
8,8 \\
6,6\end{array}$ & arenito & $\begin{array}{l}0,128 \\
\text { ar. f. }\end{array}$ & $\begin{array}{r}1,295 \\
\text { pob. } \mathrm{s} .\end{array}$ & $\begin{array}{c}0,632 \\
\mathrm{~m} .+\end{array}$ & $\begin{array}{c}3,488 \\
\text { ext. lep. }\end{array}$ \\
\hline 30 & $\begin{array}{r}94,7 \\
1,0 \\
4,2\end{array}$ & arenito & $\begin{array}{r}0,251 \\
\text { ar. med. }\end{array}$ & $\begin{array}{r}1,175 \\
\text { pob. s. }\end{array}$ & $\begin{array}{r}0,294 \\
+\end{array}$ & $\begin{array}{r}1,236 \\
\text { lep. }\end{array}$ \\
\hline 51 & $\begin{array}{r}92,5 \\
2,1 \\
5,4\end{array}$ & arenito & $\begin{array}{l}0,173 \\
\text { ar. f. }\end{array}$ & $\begin{array}{r}1,076 \\
\text { pob. s. }\end{array}$ & $\begin{array}{c}0,592 \\
\text { m. + }\end{array}$ & $\begin{array}{c}5,452 \\
\text { ext. lep. }\end{array}$ \\
\hline 52 & $\begin{array}{r}77,1 \\
13,1 \\
9,8\end{array}$ & arenito & $\begin{array}{l}0,127 \\
\text { ar. f. }\end{array}$ & $\begin{array}{r}1,820 \\
\text { pob. } \mathrm{s} .\end{array}$ & $\begin{array}{c}0,745 \\
\mathrm{~m} .+\end{array}$ & $\begin{array}{l}1,833 \\
\text { m. lep. }\end{array}$ \\
\hline 53 & $\begin{array}{r}83,8 \\
4,6 \\
11,5\end{array}$ & arenito & $\begin{array}{l}0,146 \\
\text { ar. f. }\end{array}$ & $\begin{array}{r}1,818 \\
\text { pob. } \mathrm{s} .\end{array}$ & $\begin{array}{c}0,205 \\
\mathrm{~m} .+\end{array}$ & $\begin{array}{l}1,871 \\
\text { m. lep. }\end{array}$ \\
\hline 55 & $\begin{array}{r}83,0 \\
3,4 \\
13,6\end{array}$ & arenito & $\begin{array}{l}0,112 \\
\text { ar. f. }\end{array}$ & $\begin{array}{r}1,536 \\
\text { pob. s. }\end{array}$ & $\begin{array}{c}0,621 \\
\mathrm{~m} .+\end{array}$ & $\begin{array}{l}2,936 \\
\text { m. lep. }\end{array}$ \\
\hline
\end{tabular}

(Cont. na pág. seg.) 
Rev. IG, São Paulo, 2(1) :31-38, jan./jun. 1981

\begin{tabular}{|c|c|c|c|c|c|c|}
\hline Amostra & $\begin{array}{l}\% \text { de areia } \\
\text { silte } \\
\text { argila }\end{array}$ & $\begin{array}{l}\text { Class. de } \\
\text { Sheppard }\end{array}$ & $\begin{array}{l}\text { Diam. } \\
\text { Médio } \\
(\mathrm{mm})\end{array}$ & $\begin{array}{l}\text { Grau de } \\
\text { seleção }\end{array}$ & $\begin{array}{l}\text { Grau de } \\
\text { Assimetria }\end{array}$ & Curtose \\
\hline 60 & $\begin{array}{r}92,1 \\
3,2 \\
4,7 \\
\end{array}$ & arenito & $\begin{array}{l}0,194 \\
\text { ar. f. }\end{array}$ & $\begin{array}{r}1,424 \\
\text { pob. s. }\end{array}$ & $\begin{array}{c}0,227 \\
+\end{array}$ & $\begin{array}{l}2,353 \\
\text { m. lep. }\end{array}$ \\
\hline 61 & $\begin{array}{c}79,3 \\
3,7 \\
17,0\end{array}$ & arenito & $\begin{array}{r}0,043 \\
\text { sil. gr. }\end{array}$ & $\begin{array}{r}2,374 \\
\text { m. pob. s. }\end{array}$ & $\begin{array}{c}0,820 \\
\text { m. }+\end{array}$ & $\begin{array}{l}2,863 \\
\text { m. lep. }\end{array}$ \\
\hline 67 & $\begin{array}{r}85,2 \\
11,1 \\
3,7\end{array}$ & arenito & $\begin{array}{l}0,151 \\
\text { ar. f. }\end{array}$ & $\begin{array}{r}1,309 \\
\text { pob. s. }\end{array}$ & $\begin{array}{l}0,580 \\
\mathrm{~m} .+\end{array}$ & $\begin{array}{l}2,824 \\
\text { m. lep. }\end{array}$ \\
\hline 69 & $\begin{array}{r}85,2 \\
6,2 \\
8,6 \\
\end{array}$ & arenito & $\begin{array}{l}0,133 \\
\text { ar. f. }\end{array}$ & $\begin{array}{r}1,019 \\
\text { pob. s. }\end{array}$ & $\begin{array}{c}0,335 \\
\mathrm{~m} .+\end{array}$ & $\begin{array}{l}1,706 \\
\text { m. lep. }\end{array}$ \\
\hline 80 & $\begin{array}{r}85,2 \\
6,2 \\
8,6 \\
\end{array}$ & arenito & $\begin{array}{l}0,113 \\
\text { ar. f. }\end{array}$ & $\begin{array}{r}1,247 \\
\text { pob. s. }\end{array}$ & $\begin{array}{c}0,669 \\
\text { m. }+\end{array}$ & $\begin{array}{c}4,312 \\
\text { ext. lep. }\end{array}$ \\
\hline 82 & $\begin{array}{r}71,5 \\
22,5 \\
6,0\end{array}$ & $\begin{array}{l}\text { arenito } \\
\text { síltico }\end{array}$ & $\begin{array}{r}0,108 \\
\text { ar.m.f. }\end{array}$ & $\begin{array}{r}1,970 \\
\text { pob. s. }\end{array}$ & $\begin{array}{r}0,162 \\
+\end{array}$ & $\begin{array}{r}1,274 \\
\text { lep. }\end{array}$ \\
\hline 84 & $\begin{array}{r}80,1 \\
8,7 \\
11,2\end{array}$ & arenito & $\begin{array}{c}0,094 \\
\text { ar.m.f. }\end{array}$ & $\begin{array}{r}2,040 \\
\text { m. pob. s. }\end{array}$ & $\begin{array}{c}0,804 \\
\mathrm{~m} .+\end{array}$ & $\begin{array}{l}2,295 \\
\text { m. lep. }\end{array}$ \\
\hline 88 & $\begin{array}{r}94,2 \\
3,2 \\
2,3 \\
\end{array}$ & arenito & $\begin{array}{r}0,376 \\
\text { ar. méd. }\end{array}$ & $\begin{array}{c}0,838 \\
\text { mod. s. }\end{array}$ & $\begin{array}{c}0,559 \\
\mathrm{~m} .+\end{array}$ & $\begin{array}{l}2,170 \\
\text { m. lep. }\end{array}$ \\
\hline 94 & $\begin{array}{r}74,7 \\
17,7 \\
7,6\end{array}$ & $\begin{array}{l}\text { arenito } \\
\text { síltico }\end{array}$ & $\begin{array}{r}0,100 \\
\text { ar. m. f. }\end{array}$ & $\begin{array}{r}1,850 \\
\text { pob. } \mathrm{s} .\end{array}$ & $\begin{array}{c}0,387 \\
\mathrm{~m} .+\end{array}$ & $\begin{array}{l}1,619 \\
\text { m. lep. }\end{array}$ \\
\hline 98-A & $\begin{array}{r}78,2 \\
14,9 \\
6,9 \\
\end{array}$ & arenito & $\begin{array}{r}0,094 \\
\text { ar. m. f. }\end{array}$ & $\begin{array}{r}1,432 \\
\text { pob. s. }\end{array}$ & $\begin{array}{c}0,637 \\
\mathrm{~m} .+\end{array}$ & $\begin{array}{l}2,176 \\
\text { m. lep. }\end{array}$ \\
\hline 99 & $\begin{array}{l}76,2 \\
11,9 \\
11,9 \\
\end{array}$ & arenito & $\begin{array}{r}0,112 \\
\text { ar. m. f. }\end{array}$ & $\begin{array}{r}1,723 \\
\text { pob. s. }\end{array}$ & $\begin{array}{c}0,326 \\
\mathrm{~m} .+\end{array}$ & $\begin{array}{l}1,790 \\
\text { m. lep. }\end{array}$ \\
\hline 100 & $\begin{array}{l}76,2 \\
11,9 \\
11,9\end{array}$ & arenito & $\begin{array}{r}0,103 \\
\text { ar. m. f. }\end{array}$ & $\begin{array}{r}2,148 \\
\text { m. pob. s. }\end{array}$ & $\begin{array}{c}0,340 \\
\text { m. }+\end{array}$ & $\begin{array}{l}1,762 \\
\text { m. lep. }\end{array}$ \\
\hline
\end{tabular}

abreviações $\left\{\begin{array}{lll}\text { sil. gr. } & = & \text { silte grosso } \\ \text { ar. } \mathbf{m} . \mathbf{f} . & = & \text { areia muito fina } \\ \text { ar. } \mathbf{f .} & = & \text { areia fina } \\ \text { ar. med. } & = & \text { areia média } \\ \text { mod. } \mathbf{s .} & = & \text { moderadamente selecionado } \\ \text { m. pob. s. } & = & \text { muito pobremente selecionado } \\ \text { pob. s. } & = & \text { pobremente selecionado } \\ \text { m. }+ & = & \text { muito positiva } \\ + & = & \text { positiva } \\ \text { lep. } & = & \text { leptocúrtica } \\ \text { m. lep. } & = & \text { muito leptocúrtica } \\ \text { ext.lep. } & = & \text { extremamente leptocúrtica }\end{array}\right.$


aqueles são melhor selecionados do que estes, o que também foi comprovado por SOARES (1975).

Comparando-se as amostras do Pirambóia, cujo grau de seleção varia de 1,8 a 2,8 , com as restantes, cujos valores vão de 0,8 a 2,1, pode-se adotar como critério preliminar o limite de grau de seleção 1,5 (valor médio do intervalo correspondente a um sedimento pobremente selecionado segundo FOLK \& WARD). Baseado nisto, amostras com grau de seleção inferior ao limite podem pertencer à Fm. Botucatu, e com grau superior podem pertencer à $\mathrm{Fm}$. Pirambóia. Este critério não é decisivo, porém pode ser confirmado pela assimetria e curtose.

\section{d) ASSIMETRIA}

Nas amostras da Fm. Pirambóia, constatou-se que os valores de assimetria variam de 0,11 a 0,61 , indicando assimetria positiva a muito positiva, isto é, a distribuição acha-se desviada para o lado das partículas finas. O mesmo foi observado nas demais amostras, concluindo-se, portanto, que este parâmetro não auxiliou na classificação das mesmas.

\section{e) CURTOSE}

Todas as amostras estudadas possuem curvas granulométricas do tipo unimodal, observadas através dos valores da curtose.

Nas amostras do Pirambóia, foram encontrados valores de curtose entre 1,0 a 1,5 (arenitos leptocúrticos, segundo FOLK \& WARD), mostrando tratarem-se de sedimentos mal selecionados na parte central da distribuição, o que reforça a idéia de uma origem fluvial.

Os valores de curtose superiores a 3,0 (extremamente leptocúrtica, segundo FOLK \& WARD) indicam um sedimento bem selecionado na parte central da distribuição, evidenciando um ambiente de deposição eólico. Sendo assim, pertencem à Fm. Botucatu as amostras $22-\mathrm{A}, 22-\mathrm{B}, 23,26,51$ e 80 . Estas, por sua vez, também apresentam um valor de grau de seleção inferior a 1,5 , confirmando o critério citatado anteriormente. Deste modo, as amostras $30,60,67,69$ e 88 , por apresentarem grau de seleção inferior a 1,5 e curtose muito próxima a 3,0, foram incluídas na $\mathrm{Fm}$. Botucatu.

As amostras 2, 15, 21, 52, 53, 55, $61,84,99$ e 100 foram classificadas como da Fm. Pirambóia pois os dados obtidos de grau de seleção são superiores a 1,5 e a curtose é bastante inferior a 3,0. As amostras 25 e $98 \mathrm{~A}$, embora apresentem características granulométricas mais próximas às da Fm. Botucatu que do Pirambóia, foram englobadas nesta última unidade. baseado em dados de campo (posição estratigráfica).

\section{SEDIMENTOGRAMA}

Com a finalidade de uma melhor visualização das diferenças texturais dos sedimentos, correlacionando-os com o seu ambiente de deposição, foram construídos os Sedimentogramas FREITAS (1973) de cada unidade pesquisada (Figura 2 e 3 ).

O Sedimentograma é um gráfico construído com base em percentis obtidos das curvas de frequência acumulativa das amostras, representados pelos seguintes símbolos:

$\mathrm{P}_{10}$ : valor do diâmetro correspondente a $90 \%$ em peso

$\mathrm{P}_{90}$ : valor do diâmetro correspondente a $10 \%$ em peso

$Q_{1}$ : valor do diâmetro correspondente a $75 \%$ em peso

$\mathrm{Q}_{3}$ : valor do diâmetro correspondente a $25 \%$ em peso

MD (Mediana): valor do diâmetro correspondente a $50 \%$ em peso

L.A. (Limite das admisturas finas e

$$
(\text { grossas })=\frac{Q_{1}+Q_{3}}{2}
$$

A classificação das amostras, baseada nos parâmetros estatísticos, per- 
mitiu a construção de um Sedimentograma para a Fm. Botucatu e outro para a Fm. Pirambóia.

Tais Sedimentogramas vem de encontro à classificação feita apenas com base em dados granulométricos, pois mostram configurações distintas, sugerindo que os sedimentos estudados tiveram condições diferentes de transporte e deposição, o que influiu em suas caracteristicas texturais.

Foi através do Sedimentograma que se pode estudar comparativamente a competência do transporte dos arenitos de cada unidade sedimentar, uma vez que "competência" refere'-se à habilidade de transporte em função do tamanho das partículas.

A partir deste conceito, verificouse que a parte mais representativa dos sedimentos da Fm. Botucatu, 65\% da amostra (intervalo compreendido entre $\mathrm{P}_{90}$ e $\mathrm{Q}_{1}$ ), encontra-se exclusivamente dentro da classe areia enquanto que esta mesma porcentagem representativa da $\mathrm{Fm}$. Pirambóia abrange desde a classe areia muito fina até silte.

Tem-se, portanto, que as partículas da Fm. Botucatu são mais grossas (de maior diâmetro) que as da $\mathrm{Fm}$. Pirambóia, sugerindo para a primeira um transporte mais competente que o da segunda.

Com a finalidade de se relacionar os diferentes agentes de transporte para cada unidade, quanto à seleção das partículas, estudou-se o comportamento do espaço compreendido entre $Q_{1}$ e $Q_{3}$, que representa $50 \%$ de cada amostra.

Os arenitos da Fm. Botucatu apresentam uma largura entre $Q_{1}$ e $Q_{3}$ bem menor que os da Fm. Pirambóia, sugerindo um agente de transporte mais seletivo para a primeira unidade. Quanto mai $_{\text {S }}$ estreito for o espaço entre $Q_{1}$ e $Q_{3}$, menor será a variação dos diâmetros dos grãos que compõem os arenitos, o que implica um maior selecionamento das partículas.
É importante ressaltar que nos Sedimentogramas estudados há diferença $_{S}$ no comportamento da linha da mediana (MD) e da linha do limite das admisturas (L.A.). No Sedimentograma relativo aos arenitos da $\mathrm{Fm}$. Botucatu, a mediana é quase coincidente com o limite das admisturas, com a maioria dos pontos na admistura fina, enquanto que na $\mathrm{Fm}$. Pirambóia a mediana tende a se afastar mais do limite das admisturas, para o lado da admistura fina. Esta característica estatística indica mecanismos distintos de sedimentação entre as unidades pesquisadas, sendo que a deposição da Fm. Pirambóia deu-se com um decréscimo lento de energia de transporte que contribuiu para a sedimentação de material mais fino, ao passo que a deposição dos arenitos da Fm. Botucatu ocorreu num ambiente cujo agente transportador comportouse de maneira uniforme em termos de energia.

\section{CONCLUSÕES}

O estudo destes sedimentos permite, através dos estudos sedimentológicos as seguintes conclusões:

1 - Pode-se constatar que os parâmetros estatísticos, obtidos de análises granulométricas, auxiliam na caracterização de unidade sedimentares que apresentam diferentes mecanismos de sedimentação.

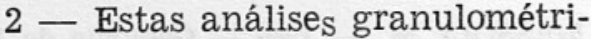
cas contribuiram para a diferenciação entre os arenitos da Fm. Botucatu e os da Fm. Pirambóia, auxiliando, assim, nos trabalhos de mapeamento geológico.

3 - Os arenitos da Fm. Pirambóia apresentam, em média, 22,8\% em peso de finos (silte + argila), ao passo que os arenitos da Fm. Botucatu contém $11,8 \%$.

4 - Os valores médios dos parâmetros $_{S}$ estatísticos de FOLK \& WARD, para cada unidade geológica são: 


\begin{tabular}{|c|c|c|c|c|}
\hline $\begin{array}{l}\text { UNIDADE } \\
\text { GEOLOGICA }\end{array}$ & $\begin{array}{c}\text { DIÂMETRO } \\
\text { MÉDIO }\end{array}$ & $\begin{array}{l}\text { GRAU DE } \\
\text { SELEÇÃO }\end{array}$ & $\begin{array}{l}\text { GRAU DE } \\
\text { ASSIMETRIA }\end{array}$ & CURTOSE \\
\hline Fm Botucatu & $\begin{array}{l}0,164 \mathrm{~mm} \\
\text { ar. f. }\end{array}$ & $\begin{array}{l}1,220 \\
\text { pob. s. }\end{array}$ & $\begin{array}{l}0,519 \\
\mathrm{~m} .+\end{array}$ & $\begin{array}{c}3,201 \\
\text { ext. lep. }\end{array}$ \\
\hline Fm Pirambóia & $\begin{array}{l}0,087 \mathrm{~mm} \\
\text { ar. m. f. }\end{array}$ & $\begin{array}{l}1,980 \\
\text { pob. s. }\end{array}$ & $\begin{array}{l}0,564 \\
\mathrm{~m} .+\end{array}$ & $\begin{array}{c}1,966 \\
\text { m. lep. }\end{array}$ \\
\hline
\end{tabular}

5 - Os Sedimentogramas contribuiram para a caracterização do transporte e deposição sofridos pelos sedimentos arenosos.

6 - O transporte sofrido pelos arenitos da Fm. Botucatu, foi de maior competência e de caráter bem mais seletivo e o dos arenitos da Fm. Pirambóia foi menos competente e menos seletivo, sendo que a deposição destes últimos deu-se com um lento decréscimo da energia de transporte.
7 - Com base nos parâmetros estatísticos de FOLK \& WARD, nos Sedimentogramas e em dados de campo, constatou-se que os ambientes de sedimentação da Fm. Botucatu e da Fm. Pirambóia foram distintos, sugerindo um ambiente eólico (deserto com campos de duna) para a primeira, e um ambiente fluvial (fácies de canal) para a segunda, concordando com SOARES (1973).

\section{BIBLIOGRAFIA}

COMPANHIA DE PESQUISA DE RECURSOS MINERAIS - 1977 - Projeto Sapucaí; relatório final: geologia. São Paulo, v. 1615 p.

FREITAS, R.O. de - 1973 - Geologia e petrologia da Formação Caiuá no Estado de São Paulo. São Paulo, Instituto Geográfico e Geológico. 122 p. (Boletim, 50).

MASSOLI, M. - 1980 - Geologia da Folha de Santa Rita do Passa Quatro. Rev. IG., São Paulo, 1(1):7-14, jan./jun.

MEZZALIRA, S. - 1965 - Folha geológica provisória de Casa Branca. São Paulo, Instituto Geográfico e Geológico. escala $1: 1.100 .000$ (SF-23-G-400).

PETROBRAS, Rio de Janeiro - 1971 - Bacia do Paraná: mapa geológico, semidetalhe do centro leste de São Paulo /por/ Sebastião Maia e Paulo Soares. Rio de Janeiro. escala 1:250.000. (Folha SF-23-G Rel. 407 - anexo 4).

SOARES, P.C. et alii - 1973 - Geologia do nordeste do Estado de São Paulo. In: CONGRESSO BRASILEIRO DE GEOLOGIA, 27. ${ }^{\circ}$, Aracaju. Anais. Aracaju, Sociedade Brasileira de Geologia. v. 1 p. 209-227.

- - 1975 - Divisão estratigráfica do Mesozóico no Estado de São Paulo. Rev. Bras. Geoc., São Paulo, 5(4):229251, dez.

SUGUIO, K. - 1973 - Introdução à sedimentologia. São Paulo, Edgard Blücher. $317 \mathrm{p}$.

WASHBURNE, C. W. $-1930-$ Petroleum geology of the State of S. Paulo by Commisão Geographica e Geológica. São Paulo, Instituto Geográfico e Geológico. 280 p. (Boletim, 22). 


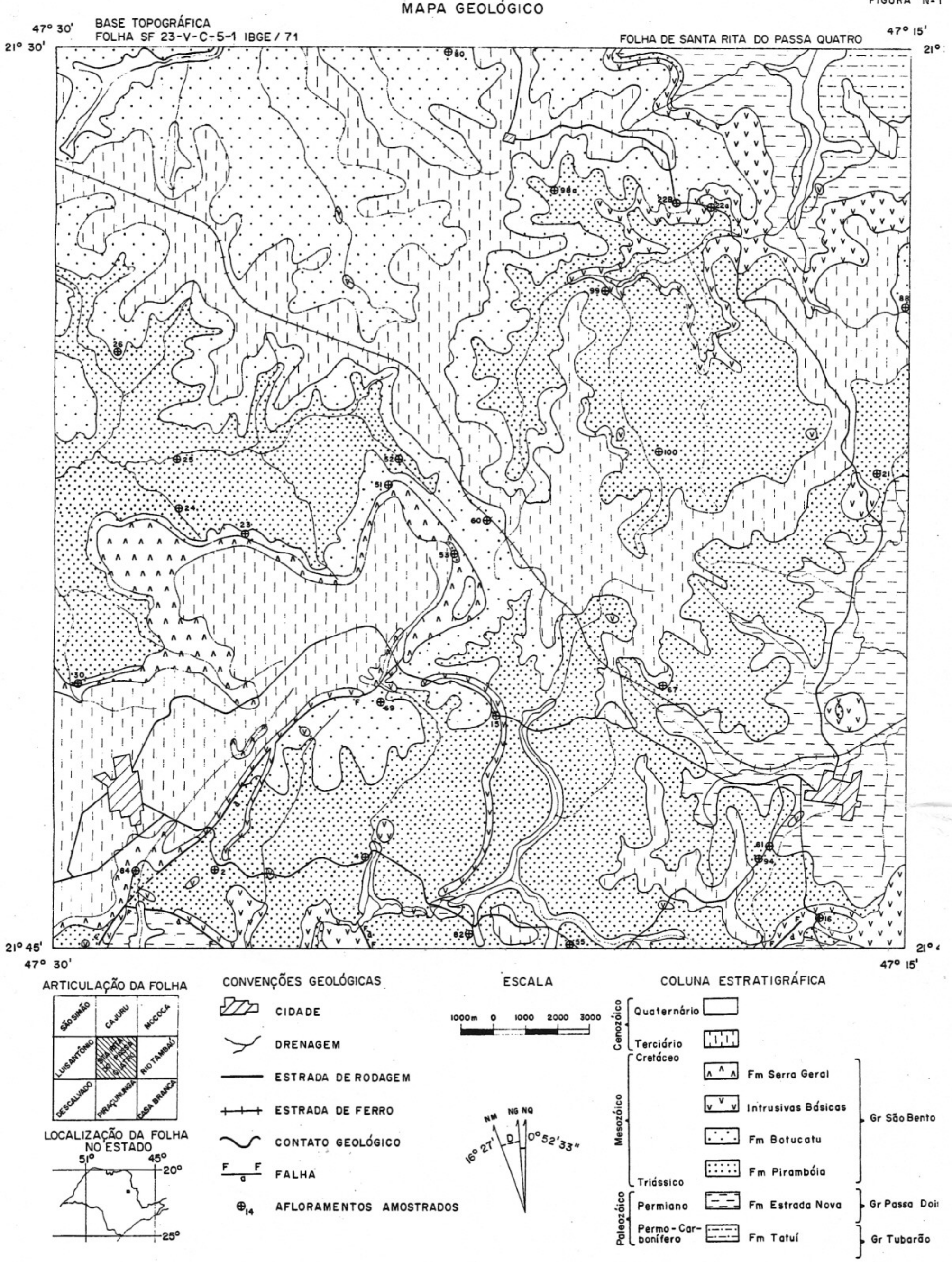




\section{SEDIMENTOGRAMA DA FORMAÇĀO PIRAMBÓIA}

FIGURA №2

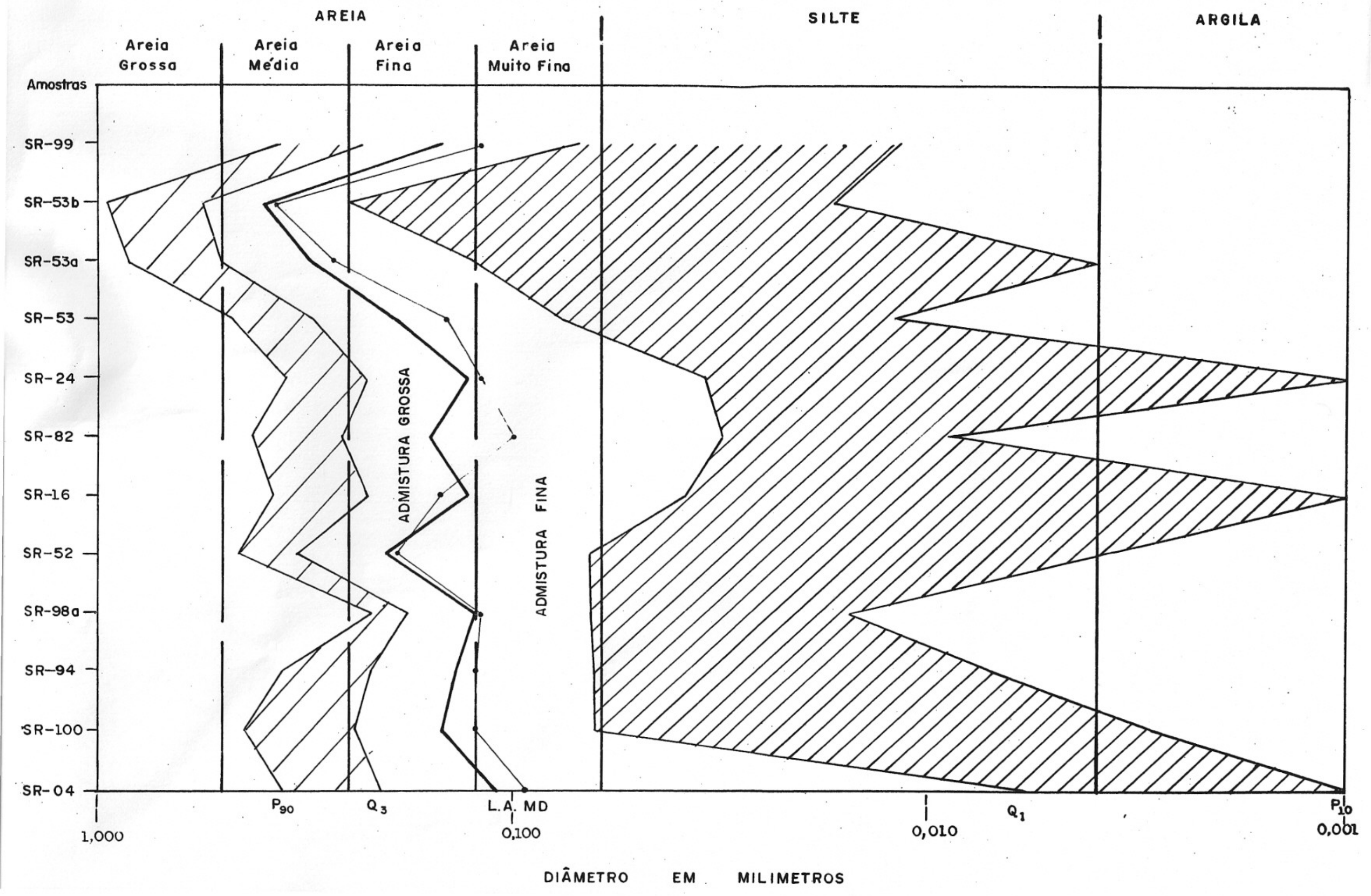




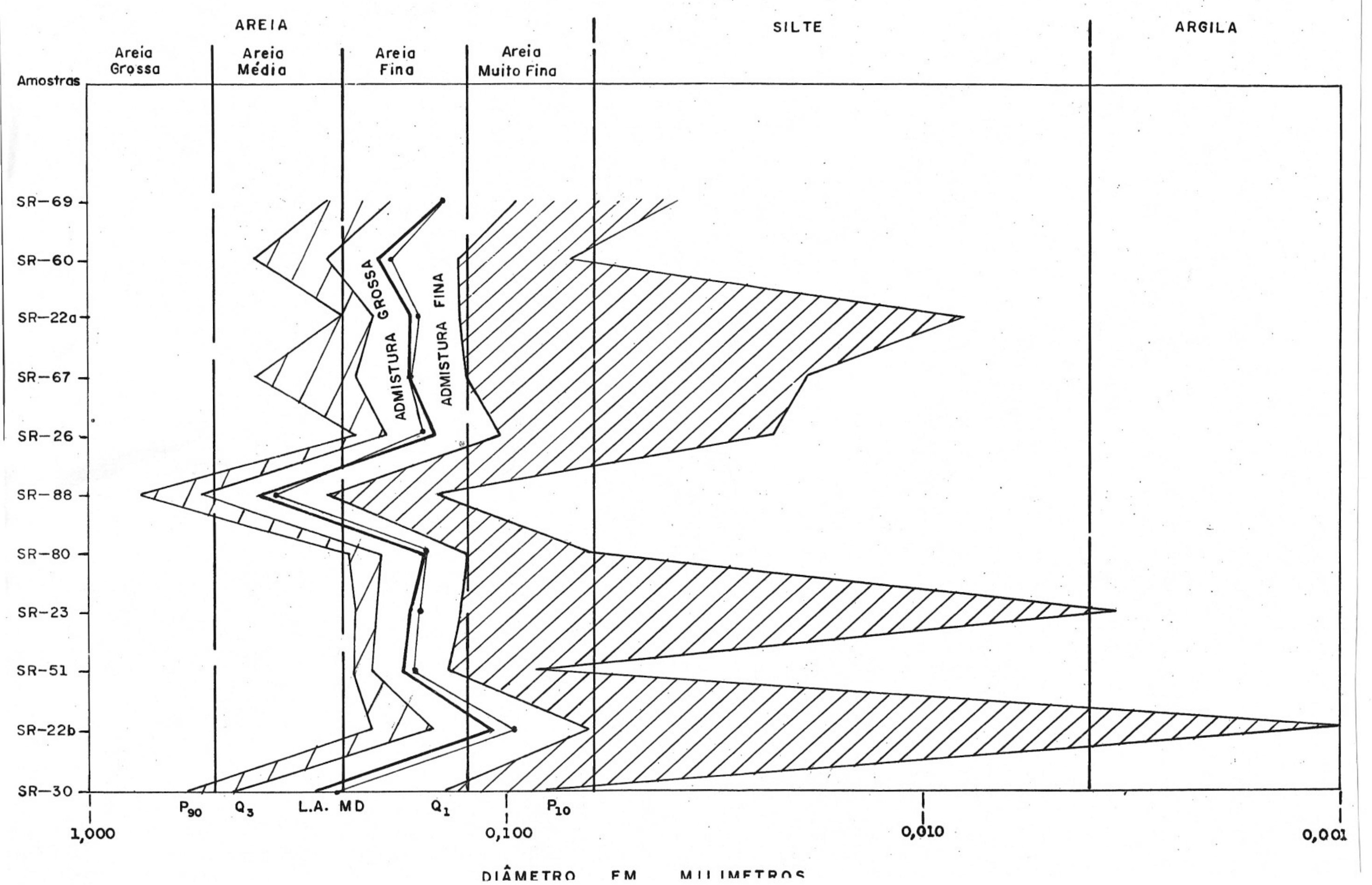

